\title{
ANALISIS USAHA DAN NILAI TAMBAH ARANG TEMPURUNG KELAPA DI KECAMATAN TEMPULING KABUPATEN INDRAGIRI HILIR
}

\author{
Reni Susilowati, Yeni Afiza \\ Program Studi Agribisnis Fakultas Pertanian UNISI \\ e-mail:reni_s@gmail.com
}

\begin{abstract}
ABSTRAK
Harga kelapa di Kecamatan Tempuling mengalami fluktuasi, hal ini menyebabkan petani harus melakukan altenatif usaha pengolahan produk turunan kelapa. Tujuan penelitian ini adalah: (1) Untuk mengetahui total biaya yang dikeluarkan dalam usaha arang tempurung di Kecamatan Tempuling, (2) Untuk mengetahui besar penerimaan dan pendapatan usaha arang tempurung di Kecamatan Tempuling, (3) Untuk mengetahui efisiensi usaha arang tempurung di Kecamatan Tempuling, dan (4) Untuk mengetahui besarnya nilai tambah usaha arang tempurung di Kecamatan Tempuling. Hasil penelitian menunjukkan bahwa (1) Rata-rata total biaya yang dikeluarkan pada usaha arang tempurung kelapa sebesar Rp. 2.834.586,57 per produksi, (2) Rata-rata penerimaan yang diterima oleh pelaku usaha arang tempurung kelapa sebesar Rp. 5.748.750,00 per produksi. Sedangkan rata-rata pendapatan sebesar Rp. 2.914.163,43 per produksi, (3) Nilai RCR (Return Cost Ratio) pada usaha pembuatan arang tempurung kelapa pada penelitan ini sebesar 2,02. Hal ini berarti usaha tersebut layak (RCR > 1), (4) Nilai tambah pada usaha pembuatan arang tempurung ini sebesar Rp. 799,02 per kilogram.
\end{abstract}

Kata Kunci: Pendapatan, Efisiensi, Nilai Tambah, Arang Tempurung Kelapa.

\section{ABSTRACT}

The prices of coconut in subdistrict of Tempuling was fluctuated, it causes the farmers to take a alternative business to be derivated product of coconut. The purposes of this research are: (1) To know total cost required from the business of coconut shell charcoal in Subdistrict of Tempuling, (2) To know revenue and income from coconut shell charcoal business in Subdistrict of Tempuling (3) To determine the efficiency of shell charcoal business in Subdistrict of Tempuling, and (4) To determine the value added of shell charcoal business in Subdistrict of Tempuling. The results are of this study showed that (1) The average total cost in the coconut shell charcoal business is Rp. 2.834.586,57 per production, (2) The average revenue in the coconut shell charcoal business is $R p$. 5.748.750,00 per production and the average profit is $R p .2 .914 .163,43$ per production, (3) The RCR value is 2,02. It's means the shell coconut charcoal business efficient., (4) Value added the shell coconut charcoal business Rp. 799,02 per kilogram.

Keywords : Profit, Efficiency, Value Added, Coconut shell charcoal

\section{PENDAHULUAN}

Indonesia merupakan negara agraris yang sebagian besar penduduknya bermata pencaharian sebagai petani. Sektor pertanian memegang peranan penting dalam struktur ekonomi nasional, karena ternyata sektor pertanian lebih tahan menghadapi krisis ekonomi dibandingkan dengan sektor lainnya. Selain itu, sektor pertanian 
berperan dalam mencukupi kebutuhan penduduk, meningkatkan pendapatan petani, penyediaan bahan baku industri, memberi peluang usaha serta kesempatan kerja, dan menunjang ketahanan pangan nasional (Adiwilaga, 1992).

Salah satu subsektor pertanian yang memegang peranan penting bagi perekonomian nasional adalah perkebunan. Kelapa (Cocos nucifera L.) merupakan salah satu komoditi perkebunan yang banyak tersebar hampir diseluruh wilayah di Indonesia dan luas arealnya pun terus meningkat. Pada tahun 1986 luas areal perkebunan kelapa baru 3.113.000 ha, maka pada tahun 1990 telah mencapai 3.334 .000 ha, dan diperkirakan pada tahun 1993 luas perkebunan kelapa mencapai 3.624.000 ha. Namun yang menjadi sentral produksinya adalah Aceh, Sumatra Utara, Riau, Lampung, Jawa Barat, Jawah Tengah, Jawa timut, Sulawesi Utara, Sulawesi Tengah, Sulawesi Selatan, NTT dan Maluku Warisno (2003) dalam Tuna (2013). Adanya potensi yang sangat besar ini harus dimanfaatkan agar tingkat pendapatan petani juga dapat meningkat (Palungkun, 2007).

Tanaman kelapa merupakan tanaman serbaguna, baik untuk keperluan pangan maupun non pangan. Setiap bagian dari tanaman kelapa bisa di manfaatkan untuk kepentingan manusia. Karena itu, pohon kelapa dijuluki sebagai The Tree of Life (pohon kehidupan) dan A heavenly Tree (pohon surga) (Rukmana, 2003).

Pemanfaatan buah kelapa masih sangat terbuka untuk dikaji dan dikembangkan lebih lanjut untuk dapat dimanfaatkan secara optimal. Meskipun hampir semua bagian dari buah kelapa dapat dimanfaatkan namun banyak pula yang terbuang menjadi sampah seprti bagian serabut dan tempurungnya.

Tempurung kelapa memiliki sifat difusi termal yang baik dibandingkan dengan bahan lain seperti kayu sehingga menjadikannya memiliki peluang besar sebagai bahan bakar pengganti. Kualitas tempurung kelapa yang baik adalah tempurung dari kelapa yang tua dan kering. Karena iti dilakukan proses pengeringan atau penjemuran sebelum diolah menjadi arang tempurung kelapa.

Perubahan tempurung kelapa menjadi arang dilakukan melalui proses prirolisis (pemanasan). Pada proses prirolisis unsur-unsur selain karbon seperti hidrogen dan oksigen akan hilang atau proses ini disebut juga dengan karbonisasi. Perubahan atau konversi tempurung kelapa menjadi arang menghasilkan karbon sisa yang banyak dan peningkatan kandungan abu namun tidak sebanyak peningkatan kandungan karbonnya. Perubahan mencolok lainnya adalah hilangnya kandungan bahan campuran (moisture) dan bahan mudah uap (volatile).

Kabupaten Indragiri Hilir merupakan salah satu penghasil kelapa terbesar di Provinsi Riau. Luas perkebunan kelapa di Kabupaten Indragiri Hilir sebesar $351.526 \mathrm{Ha}$ dengan produksi sebesar 361.348 ton (BPS Provinsi Riau Dalam Angka 2020). Namun beberapa tahun terakhir kelapa mengalami penurunan harga yang signifikan. Penurunan harga kelapa tersebut mengakibatkan petani harus mengambil alternatif usaha lain atau mengolah buah kelapa menjadi produk turunannya agar para petani dapat bertahan hidup. Harga jual kelapa dalam bentuk butiran sebesar Rp. 700 per kilogram (Agustus, 2019. Kecamatan Enok).

Kecamatan Tempuling 
merupakan salah satu dari 20 kecamatan yang ada di Kabupaten Indragiri Hilir. Kecamatan Tempuling memiliki luas wilayah 69,119 Ha yang terdiri dari empat kelurahan dan lima desa. Dengan batas wilayah, sebelah selatan berbatasan dengan Kecamatan Enok, sebelah utara berbatasan dengan Kecamatan Batang Tuaka, sebelah timur berbatasan dengan Kecamatan Tembilahan, dan sebelah barat berbatasan dengan Kecamatan Rengat Kabupaten Indragiri Hulu.

Kecamatan Tempuling memiliki luas perkebunan kelapa 13.298 ha dan rata-rata produksi $3.210 \mathrm{~kg} / \mathrm{ha}$. (BPS Kabupaten Indragiri Hilir, 2015). Kecamatan Tempuling memiliki potensi untuk mengembangkan usaha arang tempurung kelapa. Tujuan Penelitian ini adalah 1) untuk mengetahui total biaya yang dikeluarkan dalam usaha arang tempurung, 2) untuk mengetahui besar penerimaan dan pendapatan usaha arang tempurung, 3) untuk mengetahui efesiensi usaha arang tempurung, 4) untuk mengetahui besarnya nilai tambah usaha arang tempurung.

\section{METODOLOGI PENELITIAN}

\subsection{Waktu dan Tempat Penelitian}

Penelitian ini dilakukan selama lebih kurang 3 bulan yaitu bulan Desember 2019 sampai dengan bulan Februari 2020. Penelitian ini dilakukan di Kecamatan Tempuling, Kabupaten Indragiri Hilir. Penentuan lokasi penelitian ini dipilih dengan pertimbangan bahwa wilayah tersebut banyak yang melakukan usaha pengolahan arang tempurung kelapa.

\subsection{Jenis dan Sumber Data}

Jenis dan sumber pada penelitian ini adalah: a. Data Primer diperoleh dengan cara melakukan wawancara kepada petani yang melakukan usaha pengolahan arang tempurung yang ada di Kecamatan Tempuling Kabupaten Indragiri Hilir dengan panduan pertanyaan yang sudah disiapkan, biasanya disebut dengan kuisioner.

b. Data Sekunder diperoleh dari studi literatur yang relevan dengan penelitian ini seperti buku, skripsi, jurnal, badan pusat statistik dan sebagainya.

\subsection{Metode Pengambilan Data}

a. Observasi lapangan dengan melakukan pengamatan langsung ke tempat lokasi usaha pengolahan arang tempurung di Kecamatan Tempuling Kabupaten Indragiri Hilir.

b. Wawancara yaitu metode pengumpulan data dengan cara melakukan wawancara langsung kepada responden (pelaku usaha arang tempurung) menggunakan kuisioner yang telah disiapkan.

\subsection{Metode Pengambilan Sampel}

Populasi dalam penelitian ini adalah pelaku usaha arang tempurung yang berproduksi di Kecamatan Tempuling, Kabupaten Indragiri Hilir. Sampel dalam penelitian ini menggunakan metode purposive sampling sebanyak 10 orang di Kecamatan Tempuling.

\subsection{Metode Analisis Data}

\section{Biaya Produksi}

Dalam melakukan kegiatan usaha pengolahan ada biaya yang dikeluarkan yaitu biaya tetap (FC) dan biaya variabel (VC). Untuk mengetahui 
total biaya produksi secara sistematis dirumuskan sebagai berikut :

$$
\mathrm{TC}=\mathrm{TFC}+\mathrm{TVC}
$$

Dimana :

TC :Biaya total usaha (Rp/Produksi)

TFC :Biaya tetap usaha (Rp/Produksi)

TVC :Biaya variabel usaha (Rp/Produksi)

\section{Penyusutan Alat}

Untuk menghitung biaya penyusutan alat dalam usaha tani dihitung dengan metode garis lurus menurut Sinuraya (1985). Dengan rumus sebagai berikut:

$$
\mathbf{D}=\frac{\mathbf{C - S V}}{\mathbf{U L}}
$$

Keterangan :

D : Nilai penyusutan alat

C : Harga beli alat

SV : Nilai sisa alat $(20 \% \times$ nilai beli)

UL : Masa pakai

\section{Analisis Penerimaan}

Penerimaan adalah perkalian antara produksi yang dihasilkan dengan hatga jual dan biasnya produksi berhubungan negatif dengan harga, artinya harga akan turun ketika produksi berlebihan (Soekartawi, 1995). Penerimaan dapat dihitung dengan menggunakan rumus sebagai berikut :

$$
\mathbf{T R}=\mathbf{Q} \times \mathbf{P}
$$

Keterangan :

TR : Penerimaan total usaha (Rp/Produksi)

Q : Jumlah produk usaha $(\mathrm{Kg})$

$\mathrm{P} \quad$ : Harga produk usaha (Rp)

\section{Pendapatan}

Pendapatan adalah selisih penerimaan total denganbiaya total.
Dapat ditulis dengan rumus sebagai berikut :

$$
\pi=\mathbf{T R}-\mathbf{T C}
$$

Keterangan :

$$
\begin{array}{ll}
\pi & \text { : Pendapatan (Rp/Bulan) } \\
\text { TR } & \text { : Total penerimaan usaha } \\
& \text { (Rp/Produksi) } \\
\text { TC } & \text { : Biaya total usaha } \\
& \text { (Rp/Produksi) }
\end{array}
$$

\section{Pendapatan Kerja Keluarga}

Menurut Hermanto (1991), untuk menghitung pendapatan keluarga digunakan rumus sebagai berikut:

$$
\mathrm{PKK}=\pi+\mathrm{TKDK}+\mathrm{D}
$$

UL Keterangan :

PKK : Pendapatan Kerja Keluarga

$$
\text { ( } \mathrm{Rp} / \mathrm{Ha} / \mathrm{Th})
$$

$\Pi \quad$ : Pendapatan (Rp/bulan)

TKDK : Upah tenaga kerja dalam keluarga $(\mathrm{Rp} / \mathrm{Ha} / \mathrm{Th})$

D : Penyusustan Alat

\section{Efisiensi Usaha}

Menurut Soekartawi (2002), analisis Return Cost (R/C) ratio merupakan perbandingan (ratio atau nisbah) antara penerimaan (revenue) dan biaya (cost), yang dikeluarkan dalam satu kali produksi. untuk mengetahui efisiensi, maka rumus yang dipakai yaitu:

\section{Efisiensi $=\mathbf{R} / \mathbf{C}$}

Keterangan:

$\mathrm{R} \quad$ :Penerimaan total usaha (Rp/produksi)

$\mathrm{C}$ :Total biaya yang dikeluarkan (Rp/Bulan)

Kriteria yang digunakan dalam penilaian efisiensi usaha adalah :

a. R/C Ratio > 1, Usaha pengolahan minyak kelapa dinyatakan layak. 
b. $\mathrm{R} / \mathrm{C}$ Ratio $=1$, Usaha pengolahan minyak kelapa dinyatakan berada pada titik impas.

c. R/C Ratio < 1, Usaha pengolahan minyak kelapa tidak layak.

\section{Analisis Nilai Tambah}

Menurut Mangunwidjaya dan

Sailah (2009), antara proses nilai tambah dengan agroindustri ada persamaan dan perbedaaan.

Persamaanya adalah sama-sama pengolahan. Perbedaanya adalah

Tabel 1. Form Perhitungan Analisis Usaha dan Nilai Tambah Produk Arang Tempurung Kelapa dengan Metode Hayami.

\begin{tabular}{|c|c|c|}
\hline Variabel & Nilai & Cara perhitungan \\
\hline 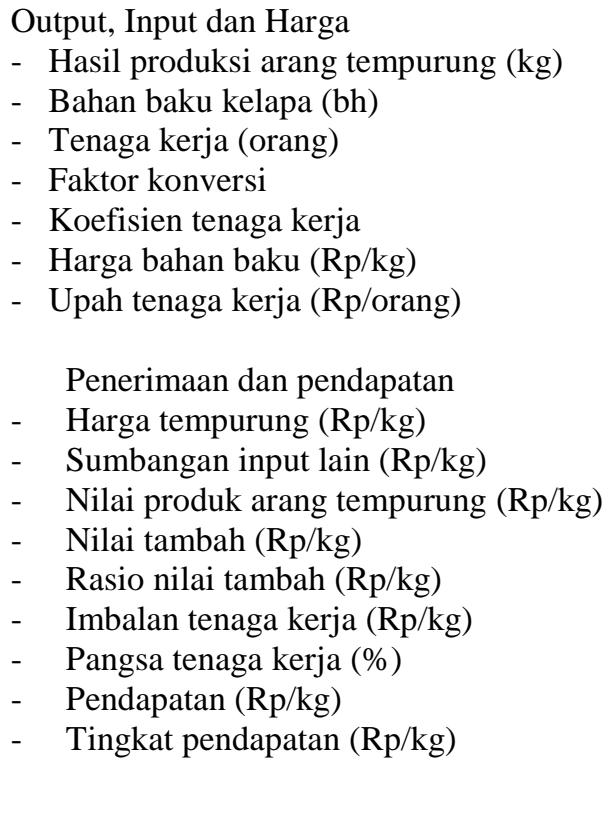 & $\begin{array}{l}11 \mathrm{a} \\
11 \mathrm{~b} \\
12 \mathrm{a} \\
12 \mathrm{~b} \\
13 \mathrm{a} \\
13 \mathrm{~b}\end{array}$ & $\begin{array}{l}=4 \times 6 \\
=10-9-8 \\
=(11 \mathrm{a} / 10) \times 100 \% \\
=5 \times 7 \\
=(12 \mathrm{a} / 11 \mathrm{a}) \times 100 \% \\
=11 \mathrm{a}-12 \mathrm{a} \\
=(13 \mathrm{a} / 11 \mathrm{a}) \times 100 \%\end{array}$ \\
\hline
\end{tabular}

Sumber: Hayami, 1987

\section{HASIL DAN PEMBAHASAN}

\subsection{Teknik Pengolahan Arang Tempurung Kelapa}

Proses pembuatan arang tempurung kelapa antara lain sebagai berikut:

1. Pengumpulan tempurung kelapa dilakukan dengan menggunakan angkong, kemudian tempurung dimasukkan kedalam drum besi, pengolahan pada analisis nilai tambah adalah hanya untuk pengolahan hasil, sedang pada agroindustri adalah pengolahan hasil dan pengolahan input pertanian. Dalam agribisnis kegiatan yang bertambah salah satu adalah agroindustri yaitu sebagian pengadaan input produksi dan kegiatan pengolahan hasil pertanian. Perhitungan nilai tambah digunakan metode hayami, ditulis sebagai berikut.

2. Pembakaran tempurung kelapa dilakukan secara bertahap, apabila tempurung yang dibakar mulai menyusut volumenya maka ditambahkan tempurung lagi. Begitu seterusnya hingga arang memenuhi drum tersebut,

3. Setelah tempurung dibakar tahap selanjutnya adalah menyiram barang tempurung menggunakan air, agar arang tak menjadi abu,

4. Kemudian arang yang sudah jadi drum ditutup menggunakan karung 
goni basah dan didiamkan untuk proses pendinginan selama beberapa waktu hingga arang tersebut dingin,

5. Setelah arang dingin tahap selanjutnya yaitu pengemasan. Pengemasan arang dilakukan dengan menggunakan karung.
Setelah dimasukkan kemudian karung diikat menggunakan tali rafia.

Berdasarkan penjelasan di atas maka dapat digambarkan urutan langkah-langkah pembuatan arang tempurung kelapa sebagai berikut:

\section{Tempurung $\longrightarrow$ Pembakaran $\rightarrow$ Penyiraman $\rightarrow$ Pendinginan $\longrightarrow$ Pengemasan}

Gambar 1: Proses Pembuatan Arang Tempurung Kelapa di Kecamatan Tempuling

\subsection{Analisis Usaha Arang Tempurung Kelapa}

\section{Biaya Produksi}

Biaya produksi merupakan biaya yang dikeluarkan oleh pengusaha arang tempurung kelapa selama melakukan kegiatan usahanya mulai dari proses produksi hingga menghasilkan produk, yang meliputi biaya tetap dan biaya tidak tetap.

Menurut Mulyadi (2012), dalam arti luas biaya adalah pengorbanan sumber ekonomisyang diukur dalam satuan uang, yang telah

Tabel 2. Analisis Biaya Produksi Usaha Pembuatan Arang Tempurung Kelapa Per Produksi

\begin{tabular}{|c|c|c|c|c|}
\hline No. & Biaya & Satuan & Harga (Rp) & Jumlah (Rp) \\
\hline \multirow[t]{9}{*}{1.} & Biaya tidak tetap & & & \\
\hline & $\begin{array}{l}\text { a. Bahan baku (3.650 } \\
\mathrm{kg})\end{array}$ & $\mathrm{Rp} / \mathrm{Kg}$ & 550 & 2.007.500,00 \\
\hline & b. Bahan bakar & Rp/Liter & 8.850 & $6.753,00$ \\
\hline & c. Bahan pengemasan & & & \\
\hline & - Karung & Buah & 15,20 & $42.800,00$ \\
\hline & - Tali rafia & Meter & 7,70 & $5.300,00$ \\
\hline & d. Biaya tenaga kerja & & 3,7 & $729.750,00$ \\
\hline & e. Biaya transportasi & & & $90.400,00$ \\
\hline & Jumlah & & & $2.882 .503,00$ \\
\hline \multirow[t]{4}{*}{2.} & Biaya tetap & & & \\
\hline & - Penyusutan alat & $\mathrm{Rp}$ & & $29.194,91$ \\
\hline & Jumlah & & & $20.194,91$ \\
\hline & Total biaya & & & 2.902.697,91 \\
\hline
\end{tabular}

terjadi atau mungkin terjadi untuk mencapai tujuan tertentu. Dalam arti sempit biaya merupakan bagian dari harga pokok yang dikorbankan dalam usaha untuk memperoleh penghasilan. Dalam penelitian ini biaya yang dimaksud adalah seluruh biaya yang dikeluarkan untuk proses pembuatan arang tempurung kelapa di Kecamatan Tempuling, baik biaya tetap maupun biaya tidak tetap. Rincian tentang biaya total yang dibutuhkan dalam melakukan usaha tersebut dapat dilihat pada Tabel 2. 


\section{a. Biaya Tetap}

(Soekartawi, 1995) Biaya tetap merupakan biaya yang nilainya relatif stabil dan harus dikeluarkan baik produksi banyak atau sedikit. Pada Tabel 2 menunjukkan bahwa biaya tetap pada usaha pembuatan arang tempurung kelapa terdiri dari biaya penyusutan alat sebesar Rp. 29.194,91. Sehingga dapat diartikan bahwa biaya tetap yang dikeluarkan pada usaha pembuatan arang tempurung kelapa sebesar Rp. 29.194,91. Martani (2012), Penyusutan adalah alokasi jumlah yang dapat disusutkan dari suatu aset sepanjang masa manfaat yang estimasi. Jumlah yang dapat disusutkan dari suatu aset adalah biaya yang dikeluarkan untuk memperoleh aset tersebut dikurangi dengan estimasi nilai sisa (salvage value) aset tersebut pada akhir masa manfaatnya. Alat-alat yang digunakan dalam usaha ini tersebut terdiri dari drum, terpal, ember, mobil pick up, gayung, garu sisir dan angkong.

\section{b. Biaya Tidak Tetap}

Biaya tidak tetap adalah biaya yang nilainya berubah-ubah tergantung dari besar kecilnya produksi yang dihasilkan (Soekartawi,1995). Pada usaha pembuatan arang tempurung kelapa di Kecamatan Tempuling biaya

Tabel 3. Komposisi Penerimaan, Pendapatan, Pendapatan Kerja Keluarga dan Efisiensi Pada Usaha Pembuatan Arang Tempurung Kelapa Di Kecamatan Tempuling

\begin{tabular}{llcr}
\hline No. & \multicolumn{1}{c}{ Uraian } & Satuan & \multicolumn{1}{c}{ Jumlah (Rp) } \\
\hline 1. & Produksi & $\mathrm{Kg}$ & 1.278 \\
2. & Harga jual & $\mathrm{Rp}$ & $4.500,00$ \\
3. & Penerimaan & $\mathrm{Rp}$ & $5.748 .750,00$ \\
4. & Biaya produksi & $\mathrm{Rp}$ & $2.834 .369,91$ \\
5. & Pendapatan (3-4) & $\mathrm{Rp}$ & $2.914 .380,09$ \\
6. & Pendapatan Kerja Keluarga & $\mathrm{Rp}$ & $2.943 .975,00$ \\
7. & Efisiensi (3:4) & & 2,02 \\
\hline
\end{tabular}

Sumber : Data primer diolah, 2020

Berdasarkan data pada Tabel 3 menunjukkan bahwa penerimaan yang diperoleh oleh pelaku usaha arang tempurung kelapa rata-rata sebesar Rp. tidak tetap terdiri dari bahan baku yaitu tempurung kelapa, bahan bakar yaitu minyak tanah atau solar atau ban motor bekas, pengemasan, transportasi dan tenaga kerja. Berdasarkan Tabel 2 menunjukkan bahwa biaya tidak tetap sebesar Rp. 2.882.503,00.

\section{c. Total Biaya}

Total biaya merupakan jumlah keseluruhan biaya yang dikeluarkan oleh pelaku usaha arang tempurung kelapa untuk melakukan proses produksinya. Total biaya adalah penjumlahan biaya tetap dan biaya tidak tetap. Dari Tabel 2 memperlihatkan bahwa total biaya yang dikeluarkan sebesar Rp. 2.902.697,91 per produksi.

\section{Penerimaan}

Penerimaan merupakan perkalian antara jumlah produksi yang dihasilkan dengan harga yang berlaku di pasar (Soekartawi, 1998). Penerimaan pembuatan usaha arang tempurung kelapa di Kecamatan Tempuling dihitung dari rata-rata yang output dihasilkan dikalikan dengan harga per kilogram output. Besarnya penerimaan pada usaha pembuatan arang tempurung kelapa per produksi dapat dilihat pada Tabel 3.
5.748.750,00 per produksi.

\section{Pendapatan}

Pendapatan usaha pembuatan 
arang tempurung kelapa di Kecamatan Tempuling merupakan selisih dari total penerimaan dengan total biaya yang dikeluarkan untuk menghasilkan produk. Besarnya keuntungan pada usaha pembuatan arang tempurung di Kecamatan Tempuling dapat dilihat pada Tabel 3 yaitu sebesar Rp. 2.914.380,09 per produksi.

\section{Pendapatan Kerja Keluarga}

Pendapatan kerja keluarga merupakan penjumlahan pendapatan, upah tenaga kerja, dan penyusutan alat. Besarnya pendapatan kerja keluarga dalam penelitian ini dapat dilihat pada Tabel 3 yaitu sebesar Rp. 2.943.975,00 per produksi.

\section{Efisiensi Usaha Arang Tempurung Kelapa}

Nilai efisiensi diperoleh dari perbandingan antara penerimaan (revenue) dan biaya yang dikeluarkan Tabel 4. Analisis Nilai Tambah Pada Usaha Pembuatan Arang Tempurung Kelapa Di Kecamatan Tempuling

\begin{tabular}{|c|c|c|c|}
\hline No. & Variabel & Perhitungan & Nilai Produksi \\
\hline & Output, Input, dan Harga & & \\
\hline 1 & Hasil produksi arang tempurung & & 1.278 \\
\hline 2 & Bahan baku tempurung $(\mathrm{Kg})$ & & 3.650 \\
\hline 3 & Tenaga Kerja (Orang) & & 3,7 \\
\hline 4 & Faktor konversi & $(1 / 2)$ & 0,35 \\
\hline 5 & Koefisien tenaga kerja & $(3 / 2)$ & 0,00101 \\
\hline 6 & Harga arang tempurung $(\mathrm{Rp} / \mathrm{Kg})$ & & 4500 \\
\hline \multirow[t]{2}{*}{7} & Upah tenaga kerja (Rp/Orang) & & $140.878,38$ \\
\hline & Penerimaan dan Keuntungan & & \\
\hline 8 & Harga tempurung $(\mathrm{Rp} / \mathrm{Kg})$ & & 550,00 \\
\hline 9 & Sumbangan input lain $(\mathrm{Rp} / \mathrm{Kg})$ & & 226,54 \\
\hline 10 & Nilai produksi arang tempurung $(\mathrm{Rp} / \mathrm{Kg})$ & $4 \times 6$ & $1.576,00$ \\
\hline $11 \mathrm{a}$ & Nilai tambah $(\mathrm{Rp} / \mathrm{Kg})$ & $(10-9-8)$ & 799,08 \\
\hline $11 b$ & Rasio nilai tambah $(\mathrm{Rp} / \mathrm{Kg})$ & $(11 \mathrm{a} / 10) \times 100 \%$ & 50,72 \\
\hline $12 \mathrm{a}$ & Imbalan tenaga kerja $(\mathrm{Rp} / \mathrm{Kg})$ & $5 \times 7$ & 142,81 \\
\hline $12 b$ & Pangsa tenaga kerja $(\%)$ & $(12 \mathrm{a} / 11 \mathrm{a}) \times 100 \%$ & 17,87 \\
\hline $13 \mathrm{a}$ & Keuntungan $(\mathrm{Rp} / \mathrm{Kg})$ & $11 \mathrm{a}-12 \mathrm{a}$ & 656,27 \\
\hline $13 b$ & Tingkat keuntungan $(\%)$ & $(13 a / 11 a) \times 100 \%$ & 82,13 \\
\hline
\end{tabular}

dalam satu kali produksi (cost). Efisiensi merupakan gambaran tidakkah usaha tersebut dilakukan. Pada usaha pembuatan arang tempurung kelapa di Kecamatan Tempuling dapat dilihat pada tabel yaitu sebesar 2,02. Hal ini berarti usaha tersebut layak untuk di lakukan karena setiap Rp. 1 biaya yang dikeluarkan akan menghasilkan pengembalian sebesar Rp. 1,02.

\section{Analisis Nilai Tambah}

Nilai tambah usaha pembuatan arang tempurung kelapa diperoleh dari nilai produksi arang dikurangi dengan lain. Analisis nilai tambah berguna untuk mengetahui berapa tambahan nilai yang terdapat pada suatu output yang dihasilkan. Nilai tambah pada usaha pembuatan arang tempurung kelapa dapat dilihat pada Tabel 4 dibawah ini: harga tempurung dan sumbangan input 
Tabel 4 menunjukkan bahwa usaha pembuatan arang tempurung membutuhkan rata-rata bahan baku sebesar $3.650 \mathrm{~kg}$ tempurung. Output yang dihasilkan rata-rata sebesar 1.278 $\mathrm{kg}$ arang per satu kali produksi. Dengan demikian konversi untuk arang tempurung kelapa adalah 0,35. Hal tersebut berarti dalam $100 \quad \mathrm{~kg}$ tempurung menghasilkan $35 \mathrm{~kg}$ arang. Jumlah rata-rata tenaga kerja yang digunakan dalam usaha ini adalah 3,7 orang. Dengan angka koefisien tenaga kerja yang diperoleh sebesar 0,00101 .

Nilai produk arang tempurung kelapa adalah Rp. 1.576 per $\mathrm{kg}$ bahan baku (diperoleh dari hasil kali faktor konversi dengan harga produk). Nilai tambah yang dihasilkan dari usaha pembuatan arang sebesar Rp. 799,08 per satu kilogram bahan baku tempurung kelapa. Nilai tambah tersebut diperoleh dari pengurangan antara nilai produksi arang tempurung, sumbangan input lain, dan haga tempurung. Rasio nilai tambah pada usaha tersebut sebesar 50,72 persen.

Sumbangan tenaga kerja yang diperoleh dari hasil kali antara koefisien tenaga kerja dan upah tenaga kerja sebesar Rp. 142,81 per kilogram. Persentase imbalan tenaga kerja terhadap nilai tambahnya adalah 17,87 persen. Keuntungan dari usaha pembuatan arang tempurung diperoleh dari pengurangan nilai tambah dengan imbalan tenaga kerja yaitu sebesar Rp. 656,27 per kilogram dengan tingkat keuntungan sebesar 82,13 persen.

\section{KESIMPULAN DAN SARAN}

\subsection{Kesimpulan}

Berdasarkan uraian dan penjelasan yang telah dikemukakan dalam hasil penelitian, maka dapat disimpulkan sebagai berikut:
1. Total biaya yang dikeluarkan pada usaha arang tempurung kelapa sebesar Rp. 2.834.369,91 per produksi.

2. Penerimaan yang diterima oleh pelaku usaha arang tempurung kelapa sebesar Rp. 4.106.250 per produksi. Sedangkan pendapatan sebesar Rp. 5.748.750,00 per produksi.

3. Nilai RCR (Return Cost Ratio) pada usaha pembuatan arang tempurung kelapa pada penelitan ini sebesar 2,02 . Hal ini berarti usaha tersebut layak (RCR > 1).

4. Nilai tambah pada usaha pembuatan arang tempurung ini sebesar $\mathrm{Rp}$. 799,08 per kilogram.

\subsection{Saran}

Sebaiknya petani kelapa dapat meningkatkan usaha pembuatan arang tempurung kelapa karena nilai tambah yang diperoleh dari usaha tersebut cukup tinggi.

\section{DAFTAR PUSTAKA}

Adiwilaga, A.1992. Ilmu Usahatani. Alumni, Bandung.

Arnita. 2017. Analisis Nilai Tambah Produk Turunan Kelapa di Desa Mumpa Kecamatan

Tempuling Kabupaten Indaragiri Hilir. Skripsi. Program Studi Agribisnis Fakultas Pertanian. Universitas Islam Indragiri. Tembilahan.

Asnawi S, Darwis SN. 1985. Prospek Ekonomi Tanaman Kelapa dan Masalahnya di Indonesia. Balai Penelitian Kelapa Terbitan Khusus: 6. Manado.

Badan Pusat Statistik Kabupaten Indragiri Hilir. 2015. (Diakses pada tanggal 06 Mei 2020). 
Badan Pusat Statistik Kabupaten Indragiri Hilir, Kecamatan Tempulig Dalam Angka. 2016. (Diakses pada tanggal 11 Juni 2020)

Badan Pusat Statistik Provinsi Riau Dalam Angka. 2020. (Diakses pada tanggal 07 Mei 2020).

Harmanto dan Zulkifli. 2003. Manajemen Biaya. BPFE. Yogyakarta.

Ignatius, dkk. 2010. Upaya Penerapan Teknologi Pengolahan Arang Tempurung Kelapa Untuk Meningkatkan Niai Tambah Petani Di Kecamatan Sei Raya Kabupaten Bengkayang. Jurnal IPREKAS. 9(2)8.13. Bengkayang.

Mangunwidjaja, D. Dan Sailah,I. 2009. Pengantar Teknologi Pertanian. Penebar Swadaya. Bogor.

Mosher, A.T. 1983. Menggerakan dan Membangun Petani. Yayasan Guna. Jakarta.

Neeke, Hasnun, dkk. 2015. Analisis Pendapatan Dan Nilai Tambah
Kelapa Menjadi Kopra

Di Desa Bolubung Kecamatan

Bulagi Utara Kabupaten

Banggai Kepulauan. e-J. Agrotekbis 3(4):532-542, Agustus 2015.

Palungkun, R. 2007. Aneka Produksi Olahan Kelapa. Penerbit Penebar Swadaya. Jakarta.

Rahardi. 1999. Agribisnis Tanaman Buah. Penebar Swadaya. Jakarta.

Rukmana, H Rahmat. 2003. Aneka Olahan Kelapa. Kanisius. Yogyakarta.

Saediman, dkk. 2018. Analisis Nilai Tambah Pengolahan Kopra Di Desa Waepandan, Kecamatan Kepala Madan Kabupaten Buru Selatan. JIA 2018:3(3):74-78. 20 November 2019. Maluku.

Said, dkk. 2001. Manajemen Teknologi Agribisnis Kunci Menuju Daya Saing Global Produk Agribisnis. PT Ghalila Indonesia dengan MMA IPB. Bogor. 